\title{
SELEÇÃO DO SUPORTE DE IMOBILIZAÇÃO DA LIPASE DE Candida rugosa VISANDO A HIDRÓLISE DO ÓLEO DE GORDURA RESIDUAL NA SÍNTESE DE BIODIESEL POR HIDROESTERIFICAÇÃO
}

\author{
C.M.P.O. EMIDIO ${ }^{1}$, L.K. SANTOS ${ }^{2}$, A. J. SCHWANKE ${ }^{3}$, S. PERGHER ${ }^{3}$, D. L. \\ FLUMIGNAN $^{2}$, A. V. PAULA ${ }^{1}$ \\ ${ }^{1}$ Universidade Estadual Paulista “Júlio de Mesquita Filho”, Departamento de Bioprocessos e \\ Biotecnologia \\ ${ }^{2}$ Universidade Estadual Paulista - Instituto de Química de Araraquara, Departamento de \\ Química Orgânica - CEMPEQC \\ ${ }^{3}$ Universidade Federal do Rio Grande do Norte, Departamento de Engenharia de Materiais \\ E-mail para contato: camile.emidio@gmail.com, ariela@fcfar.unesp.br
}

\begin{abstract}
RESUMO - As lipases são enzimas capazes de hidrolisar triacilgliceróis transformando-os em ácidos graxos livres e glicerol, o que possibilita sua aplicação na reação de hidrólise de óleos e gorduras residuais (OGR). O OGR é uma matéria prima para produção do biodiesel que apresenta como vantagens a redução do custo de produção pelo seu baixo valor de mercado e o reaproveitamento de resíduo, contribuindo para um desenvolvimento sustentável. Neste trabalho, objetivou-se a seleção de um imobilizado de lipase de Candida rugosa visando-se maximizar a hidrólise do OGR. Foram avaliados diferentes suportes de imobilização (caulim e argila montimorillonita KSF comercial) a partir da metodologias de imobilização em meio aquoso. As reações de hidrólise foram conduzidas na temperatura de $45^{\circ} \mathrm{C}$, por $6 \mathrm{~h}$, empregando razão água:óleo 3:1 (v/v). As reações foram acompanhadas pelo teor de ácidos graxos livres, calculando-se o grau de hidrólise (\%). O imobilizado que apresentou melhor resultado foi o suporte montimorillonita KSF comercial, sua conversão em ácidos graxos em 6 horas alcançou 43,01\%. Portanto, a lipase de Candida rugosa, imobilizada possui viabilidade para sua aplicação na hidrólise de OGR visando à síntese de biodiesel.
\end{abstract}

\section{INTRODUÇÃO}

As lipases são denominadas de glicerol ésteres hidrolases e pertencem ao grupo das hidrolases. A partir dessas enzimas os triacilgliceróis sofrem um processo de hidrólise em três etapas, inicialmente são transformados em diacilgliceróis, em seguida a monoacilgliceróis e glicerol em todas as etapas são produzidos ácidos graxos livres (SANTOS, 2015).

Trata-se de um grupo importante de enzimas para aplicações biotecnológicas em diversos setores como de detergentes, têxtil, alimentício, farmacêutico, cosmético, indústrias de papel e biocombustíveis (FERREIRA-DIAS, 2013). 
No campo dos biocombustíveis as lipases podem ser aplicadas na hidrólise de óleos vegetais ou gorduras animais para produção do biodiesel. O biodiesel vem se consolidando no mercado mundial como uma alternativa sobre os combustíveis petroquímicos pois possui algumas características vantajosas, tais como, alto número de cetano; baixo conteúdo de enxofre e de compostos aromáticos, maior ponto de fulgor, teor médio de oxigênio, caráter não tóxico e biodegradabilidade, menor emissão de partículas de $\mathrm{HPA}, \mathrm{CO}$ e $\mathrm{CO}_{2}$, além de ser proveniente de fontes renováveis (BAGLEY,1998; HAAS, 2001; PETERSON, 2002).

O processo de hidroesterificação é a técnica mais atual na produção de biodiesel, consistindo numa reação de hidrólise seguida por uma reação de esterificação. Esse processo possibilita o uso de qualquer matéria-prima graxa, independentemente dos teores de acidez e umidade (SANTOS, 2015).

Com a hidroesterificação, o reaproveitamento do OGR na produção de biodiesel se torna uma possibilidade para redução do custo da matéria-prima diminuindo o valor de mercado e de conscientização sobre a importância da preservação ambiental, pois reaproveita um resíduo e o transforma em uma alternativa energética, contribuindo para um desenvolvimento sustentável menos poluente (COSTA NETO, 2001).

\section{OBJETIVO}

Avaliar a viabilidade de aplicação de lipases inespecíficas, imobilizadas em diferentes suportes, na reação de hidrólise do óleo de gordura residual para a síntese de biodiesel por hidroesterificação.

\section{MATERIAIS E MÉTODOS}

Matérias Primas: o óleo de gordura residual utilizado no projeto foi cedido pelo Instituto Federal de Educação, Ciência e Tecnologia de São Paulo, Campus Matão. As enzimas são lipases Candida rugosa (L1754, EC. 3.1.1.3, tipo VII, atividade hidrolítica 3577,46 U/g, teor de proteína $16 \% \mathrm{~m} / \mathrm{m}$ ) obtida da Sigma-Aldrich e Candida antartica da Novozymes, e os suportes de imobilização foram Caulim e Montimorillonita KSF comercial cedidos pelo Laboratório de Peneiras Moleculares (LABPEMOL) da Universidade Federal do Rio Grande do Norte.

\subsection{Imobilização em meio aquoso}

Para imobilização por adsorção física, em meio aquoso, a enzima foi solubilizada em uma solução tamponante de fosfato com pH 7 e $25 \mathrm{Mm}$. Submeteu-se a solução enzimática numa proporção suporte/enzima de $0,5 \mathrm{~g} / 10 \mathrm{ml}$ em um tubo falcon. $\mathrm{O}$ tubo permaneceu em agitação por 24 horas em temperatura ambiente. Após as $24 \mathrm{~h}$ centrifugou-se a $5000 \mathrm{rpm}$ por 10 min e separou o imobilizado (PAULA, 2012).

\subsection{Determinação da atividade hidrolítica}

A dosagem da atividade enzimática foi realizada através da metodologia descrita por Paula (2012). 


\subsection{Rendimento de imobilização da lipase}

O rendimento da imobilização da lipase foi calculado usando a Equação 2 (PAULA, 2012):

$$
\eta(\%)=\frac{\mathrm{U} \times 100}{\mathrm{U}_{0}}
$$

Em que: $\mathrm{U}=$ unidades de atividade hidrolítica total no derivado imobilizado, Uo $=$ unidades de atividade hidrolítica oferecidas para imobilização.

\subsection{Aplicação dos derivados imobilizados em reações de hidrólise em óleo de gordura residual}

Para as reações de hidrólise em óleo de gordura residual, preparou-se uma emulsão de 2,5 g de óleo, 7,5 g solução tampão fosfato $\mathrm{pH} 7$ e $0,075 \mathrm{~g}$ de goma arábica com 2,5\% de catalisador em relação a massa total. A mistura foi inserida em um reator de $50 \mathrm{~mL}$, que foi mantido sob agitação moderada, sob temperatura de $45^{\circ} \mathrm{C}$, por 6 horas. A cada duas horas foi retirado uma alíquota de aproximadamente $0,5 \mathrm{~g}$ da fase orgânica e determinado o teor de ácidos graxos livres e índice de acidez.

\section{5. Índice de Acidez}

Adicionaram-se $10 \mathrm{ml}$ de álcool e duas gotas do indicador fenolftaleína na alíquota retirada da reação de hidrolise do OGR em frasco Erlenmeyer de $125 \mathrm{~mL}$. Em seguida titulouse com uma solução de hidróxido de sódio 0,1 M (SILVA, 2010). A estimativa do índice de acidez em $\mathrm{mg}$ de $\mathrm{KOH} / \mathrm{g}$ de óleo foi calculada segundo a Equação 3.

$$
I A=\frac{V^{*} F^{*} 5,61}{P}
$$

$\mathrm{V}=$ volume de solução de hidróxido de sódio $0,1 \mathrm{M}$ gasto na titulação, $\mathrm{F}=$ fator da solução de hidróxido de sódio, $\mathrm{P}=$ massa da amostra $(\mathrm{g})$

\section{RESULTADOS}

A lipase de Candida rugosa foi imobilizada por adsorção física em meio aquoso, em dois suportes Montimorillonita KSF Comercial e Caulim. Ambos os derivados imobilizados apresentaram diminuição da atividade hidrolítica, em relação ao valor fornecido pela lipase na forma livre, conforme dados apresentados na Tabela 1 . 
Tabela 1: Atividade hidrolítica da lipase de Candida rugosa livre e imobilizada em diferentes suportes.

\begin{tabular}{lcc}
\hline \multicolumn{1}{c}{ Catalisador } & Atividade Hidrolítica (U/g) & $\begin{array}{c}\text { Rendimento de } \\
\text { Imobilização (\%) }\end{array}$ \\
\hline Candida rugosa livre & 3377,46 & - \\
Candida rugosa imobilizada em Caulim & 232,9 & 33,63 \\
Candida rugosa imobilizada em Mont. KFC & 96,96 & 14,01 \\
\hline
\end{tabular}

Analisando os dados da Tabela 1, a lipase de Candida rugosa imobilizada que forneceu maior atividade foi imobilizada em suporte o caulim, com rendimento de imobilização de 33,63 \%. Segundo os dados encontrados da literatura (PAIVA, 2008), o suporte caulim está sendo considerado para as imobilizações de lipases devido sua afinidade e baixo custo e a argila Montimorillonita a elevada capacidade de troca catiônica e a capacidade de expansão interlamelar.

Todos os sistemas imobilizados foram empregados como catalisadores da reação de hidrólise do óleo de gordura residual apresentando como resultado os teores de acidez (Tabela 2) e comportamento de conversão do óleo em ácidos graxo livres em decorrer do tempo (Gráfico 1).

Tabela 2: Acidez no meio reacional da hidrolise do OGR ao decorrer do tempo nos imobilizados de Candida rugosa.

\begin{tabular}{|c|c|c|c|}
\hline Catalisador Enzimático & $\begin{array}{c}2 \text { horas } \\
\text { Acidez } \mathrm{mg} \mathrm{NaOH} / \mathrm{g}\end{array}$ & $\begin{array}{c}4 \text { horas } \\
\text { Acidez } \mathrm{mg} \mathrm{NaOH} / \mathrm{g}\end{array}$ & $\begin{array}{c}6 \text { horas } \\
\text { Acidez } \mathrm{mg} \mathrm{NaOH} / \mathrm{g}\end{array}$ \\
\hline Candida rugosa - Caulim & 40,99 & 63,29 & 73,78 \\
\hline Candida rugosa - Mont & 52,75 & 63,72 & 85,59 \\
\hline
\end{tabular}

A hidrólise do substrato, que nesse caso é o triaciglicerol, ocorre via hidrólise sequencial dos grupos acila do glicerídeo liberando diacilgliceróis, monocilgliceróis, glicerol e ácidos graxos ocasionando o aumento de acidez no meio durante o decorrer do tempo.

Os resultados revelaram que a conversão máxima em 6 horas obtida empregando caulim e Montmorillonita KSF como suportes, foram 37,3 \% e 43,01\%, respectivamente. Comparando os imobilizados com a Novozym 435 - Candida antártica imobilizada - enzima com $8000 \mathrm{U} / \mathrm{g}$ de atividade hidrolítica, pode-se observar que a enzima Novozym 435 forneceu um valor de hidrolise muito menor que a Candida rugosa, isso pode ser decorrente de ser uma enzima 1-3-especifica. Segundo os dados encontrados por Talukder et al. (2010) a lipase Candida rugosa hidrolisou $99 \%$ do óleo residual após $10 \mathrm{~h}$ de reação. O reuso dos imobilizados não foi realizado no presente trabalho, porém está previsto nas próximas etapas da pesquisa. 
Gráfico 1: Conversão do OGR em ácidos graxos livres dos imobilizados de Candida rugosa em caulim e Montimorillonitta KFC da enzima Novozym 435

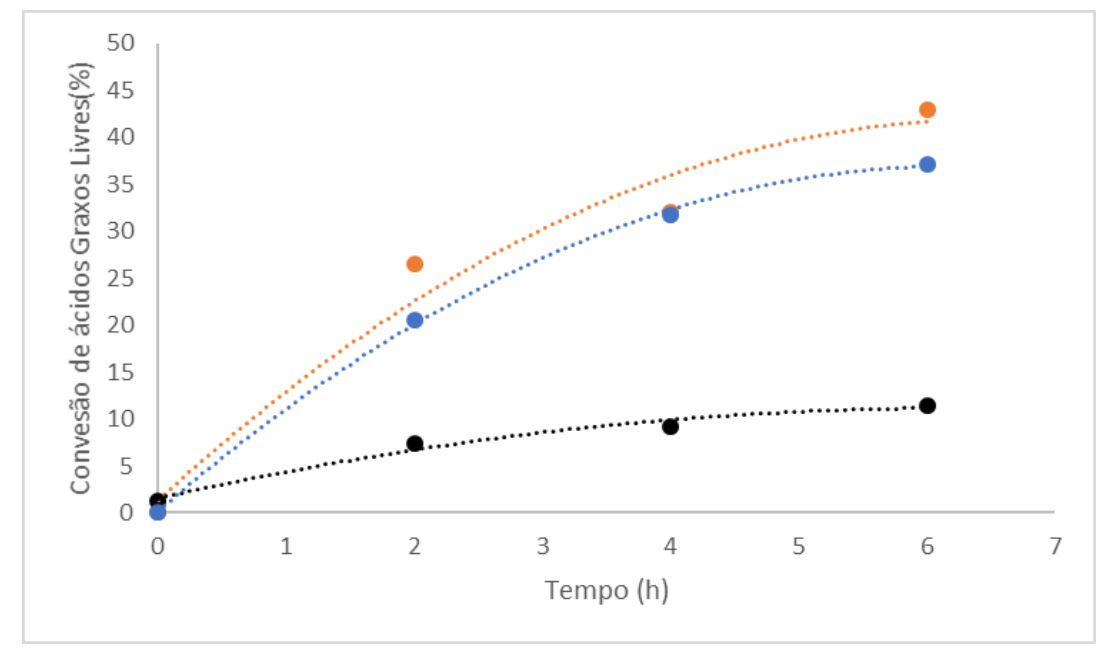

Legenda: O ícone $\bullet$ representa o suporte caulim e $\bullet$ o suporte Montimorillonitta KFC e o Novozym 435.

\section{CONCLUSÃO}

A partir deste estudo, observamos a viabilidade da aplicação da enzima Candida rugosa na hidrólise do óleo de gordura devido sua conversão de 43,01 \% em 6 horas dado que corrobora a literatura já existente e possibilita sua aplicação na síntese de biodiesel por hidroesterificação.

\section{REFERÊNCIAS}

BAGLEY, S. T.; GRATZ, L. D.; JOHNSON, J. H.; MCDONALD, J. F.; Effects of an oxidation catalytic converter and a biodiesel fuel on the chemical, mutagenic, and particle size characteristics of emissions from a diesel engine Environ. Sci. Technol. 1998, 32, 1183

COSTA NETO, P. R. Obtenção de lipídeos estruturados por interesterificação de triacilgliceróis de cadeia média e longa. 2001, 185p.

FERREIRA-DIAS, S.; SANDOVAL, G.; PLOU, F.; VALERO, F. The potential use of lipases in the production of fatty acid derivatives for the food and nutraceutical industries. Eletronic Journal of Biotechnology, v. 17, nº 3, p. 1-38, 2013.

GOMES, F. M. et al. Determinação das propriedades catalíticas em meio aquoso e orgânico da lipase de Candida rugosa imobilizada em celulignina quimicamente mod.ificada por carbonildiimidazol. Quím. Nova, São Paulo, v. 29, n. 4, p. 710-718, July 2006

HAAS, M. J.; SCOTT, K. M.; ALLEMAN, T. L.; MCCORMICK, R. L.; Energy Fuels $2001,15,1207$ 
PAIVA, L. B. de; MORALES, A. R.; DIAZ, F. R. V.. Argilas organofílicas: características, metodologias de preparação, compostos de intercalação e técnicas de caracterização. Cerâmica, São Paulo, v. 54, n. 330, p. 213-226, June 2008

PAULA, A. V. Reestruturação da gordura de leite por Interesterificação enzimática empregando lipase imobilizada: otimização das condições reacionais e operacionais. 2011. 212 p. Tese (Doutorado em Ciências) - Escola de Engenharia de Lorena, Universidade de São Paulo, Lorena/SP, 2012.

PETERSON, C. L.; COOK, J. L.; THOMPSON, J. C.; TABERSKI, J. S.; Continuous flow biodiesel production Appl. Eng. Agric. 2002, 18, 5.

SANTOS, L.K., et al.; Estado da arte da aplicação do processo de hidroesterificação na produção de biodiesel a partir de matérias-primas de baixa qualidade. Principia, [s.l.], v. 1, n. 28, p.178-190, 31 dez. 2015. Instituto Federal de Educação, Ciência e Tecnologia da Paraíba.

SILVA, G. S. Imobilização de lipase em matriz polimérica para produção de bioaroma. Dissertação (Mestrado) - Faculdade de Zootecnia e Engenharia de alimentos, Universidade de São Paulo, Pirassununga/SP, 2010.

TALUKDER M. M. R., WU J. C., FEN N. M., MELISSA Y. L. S., “Two-step lipase catalysis for production of biodiesel," Biochemical Engineering Journal, vol. 49, no. 2, pp. 207-212, 2010. 